\title{
FILOSOFIA DEL RIESGO: CRÓNICA DE LA MODERNIDAD
}

\author{
Maximilano Korstanje \\ Universidad de Palermo, Argentina
}

\begin{abstract}
Resumen: El presente ensayo reflexiona sobre el papel que el riesgo juega en nuestra vida diaria, desde varias perspectivas, no desde un punto de vista vinculante del peligro sino como una estrategia de difusión y persuasión para desdibujar la línea moral entre la decisión y sus consecuencias. A mayor racionalidad, mayor la desprotección percibida. La tesis principal del presente trabajo es que en una sociedad post-capitalista, donde el seguro domina las relaciones humanas, el riesgo (como forma estereotipada del miedo) se transforma en el requisito primordial y funcional de las formas modernas de producción. Todos, casi sin excepción, tememos en mayor o menor medida al viaje porque éste nos conduce más allá de nuestras certidumbres. Las sociedades nómadas que exploraban el terreno no tenían ese problema, el temor por lo diferente comienza sin lugar a dudas, con el asentamiento y la muralla de las grandes ciudades.
\end{abstract}

Palabras clave: riesgo, peligro, seguridad, temor, modernidad, discurso.

\section{Philosophy of risk: Chronicles of modernity}

\begin{abstract}
Throughout this essay, the risk and its function in our daily life are in depth examined from various perspectives, not only linked to a threatening nature but as a strategy of dissuasion to blurs the moral boundaries between decision and its consequences. The larger the rationale, greater the sentiment of unprotection. The thesis of this paper is that in a postmodern society, enrooted in the hegemony of insurances as mediator of human's relationships, the risk (as a stereotype of fear) becomes in a crucial factor to enhance the existent form of productions. Everybody of us frights to physical displacement because it leaves us beyond our home certainty. The nomads groups that million years ago explored the territory have not experienced panic to uncertainty, the fear for the diversity started with sedentary civilization and the creation of walls which characterize the life in greatest cities.
\end{abstract}

Keywords: risk, danger, safety, fear, modernity, discourse

El riesgo se define como una categoría que modera los efectos negativos de la incertidumbre sobre el organismo y sobre su psicología. Los abordajes contemporáneos han hecho del riesgo una cuestión de probabilidad; no obstante, esta postura es errónea porque presupone que todos los seres humanos tenemos acceso a la totalidad de las causas que fundamentan la probabilidad de evitar un peligro. Por otro lado, si coincidimos el sujeto no tiene total control sobre su propia previsibilidad debe confiar y en ese acto se entrega al riesgo ${ }^{1}$ no como amenaza

\footnotetext{
${ }^{1}$ Giddens, A. Modernity and Self-Identity: Self and Society in the Late Modern Age. California, Stanford University Press, 1991 - Giddens, A. Consecuencias de la Modernidad. Madrid, Alianza Editorial, 1999 - Giddens, A. The Politics of Climate Change. Cambridge, Polity Press, 2011.
} 
en sí mismo sino como institución construida. Pero el riesgo también puede convertirse en un mecanismo que involucre al consumo masivo y a la propaganda como formas de alienación del individuo. Ese precisamente el caso de las diferentes publicidades apuntaladas con el fin de introducir en la mente del consumidor una necesidad. Dicha necesidad se basa en lo que he denominado principio de "catástrofe" por el cual se visualiza el peor escenario para demoler las diferentes barreras cognitivas de la "víctima". Este tipo de técnica discursiva tiene como función desdibujar las fronteras entre lo probable y lo posible. Si bien, es siempre posible que un avión de línea comercial caiga con 200 pasajeros y no sobreviva ninguno, este hecho es improbable. Por el contrario, la probabilidad siempre se encuentra anclada a un potencial peligro. Lo probable es evitable, lo cual conlleva una carga emotiva muy pequeña porque el sujeto está convencido que conduciéndose de determinada manera se puede evitar el peligro; pero lo posible, se encuentra fuera de las líneas de acción ya que por intempestivo destruye el principio de causalidad. Lo que más nos angustia de lo posible de morir, no es la muerte misma, sino que sabemos volverá a ocurrir en otro momento pero si saber con exactitud cuando. A grandes rasgos, mientras lo probable evoca al riesgo y a una baja carga emocional, lo posible implica un peligro y una alta carga emocional. Los medios masivos de comunicación y los expertos en mercadotecnia se han dado cuenta los beneficios que incluye la mezcla entre lo probable y lo imposible. Cuando nuestra mente prefigura que eventos de alto impacto son altamente probables, el pánico y el terror se apoderan de ella.

La televisión y los programas educativos hacen referencia a los virus como potenciales pandemias mortales que deben ser detenidas ${ }^{2}$. Desde el momento en que nadie sabe cuanto ni como esos virus van a "atacar" (véase que la mayoría de estas publicidades utilizan términos castrenses como seguridad, ataque, blanco), uno debe tomar una actitud proactiva comenzando una "guerra preventiva" contra estos pequeños organismos. Parte de nuestra locura por estos microorganismos se ve determinada por lo minúsculos que son, y por la dificultad de evitarlos. Aquí cabe señalar, el principio de contingencia se encuentra inextricablemente asociado a la evitación, tendemos a temer por aquello que se escapa a nuestro control. Estos dispositivos de publicidad antes mencionado, propagan el temor por medio de dos canales, la producción económica y la protección de los hijos. La particularidad y selectividad de estas narrativas apuntan al "temor" infundido en padres con poder adquisitivo suficiente para consumir productos de determinada naturaleza. Las sociedades modernas enfatizan en la seguridad de los niños, cuanto más pequeños mejor, como el valuarte más representativo de su negación por la muerte. Pero esta negación, no está vinculado a un estrecho vínculo de amor filiar sino basado en un sentimiento de exclusión, narcisismo y egoísmo. La negación de la muerte es para occidente uno de sus mayores tabúes. Pero no sólo ello, la mayoría de las personas incluso pretenden deshacerse del dolor

\footnotetext{
${ }^{2}$ Korstanje, M. "Swine Flu in Buenos Aires: beyond the principle of Resilience". Int. Journal of Disasters Resilience in the built environment. Vol. 2, No. 1, 2011, pp. 59-73. - Baudrillard, J. The Gulf War did not take place. Sydney, Power Publications, 1995.
} 
(maximizando el placer) en todos los campos de la vida. La histeria por la protección de la progenie no tiene nada que ver con cuestiones de biología o supervivencia sino más bien por cuestiones que hacen a la necesidad de atención y excepcionalidad. Lo catastrófico tiene un doble sentido, primero, nos señala a nosotros, insignificantes organismos de entre toda la magnificencia de la naturaleza y el cosmos; en segundo lugar, abre la puerta a una oportunidad de redención, muy similar al de los héroes clásicos. Quien muere o sobrevive en circunstancias de extrema emergencia puede ser llamado "excepcional". Aquí cabe una pregunta ante la muerte del hijo: ¿qué preferirías ver morir a tu hijo y vivir con ese dolor toda tu vida?, o ¿qué tu hijo viva con el dolor de verte morir a ti toda la suya?. La primera pregunta confluye en un mar que lleva directamente hasta el estoicismo, mientras la segunda en el egoísmo. Lo que por regla común se nos presenta como algo necesario, la protección de los niños es en el fondo una articulación de diferentes mecanismos discursivos cuyo fin último radica en crear una narrativa que no solo niega a la muerte como una posibilidad entre otras, sino acrecenta el narcisismo.

\section{II}

La muerte de Dios es producto de nuestra propia necesidad de avance técnico; la misma Reforma nace de la imposibilidad de la religión para explicar un mundo complejizado ${ }^{3}$. En esta sección del trabajo no vamos a especular hasta que punto la existencia y/o inexistencia de una deidad superior condiciona "el buen vivir" sino la relación histórica entre los mecanismos de seguridad conferidos al ciudadano y el declinar de la creencia. S. Zizek admite, en la modernidad creemos más que nunca, hasta el punto de tener que tildar con comillas un texto cuando no es de la autoría de uno mismo ${ }^{4}$. La religión nace del secreto o del misterio de no saber. Dicha creencia se encuentra patrimonalizada por medio de las esculturas y la arquitectura edilicia de edicificios cuya monumentalidad atrae pero no convencen. Es el caso de los miles de turistas que visitan diariamente las catedrales europeas sin estar convencidos de la existencia de Dios. En otros abordajes, se ha identificado al agnosticismo como el causante de la inflación de riesgo ${ }^{5}$.

Si Dios, creador y protector de los hombres se predisponía a cuidarlos en momentos de incertidumbre, su muerte sugiere que un lugar ha quedado vacío. Una de las explicaciones más convincentes sobre el progresivo declinar de la fe cristina, ha estado a cargo de James Turner quien analiza el fenómeno dentro de los Estados Unidos. ¿Cómo un país tan creyente ha podido convertirse en una nación totalmente atea?, se pregunta Turner en su libro without God Without

\footnotetext{
${ }^{3}$ Turner, J. Without God, without Creed: the origin of unbelief in America. Baltimore, The John Hopkins University Press, 1986

${ }^{4}$ Zizek, S. El Títere y el Enano. El Núcleo Perverso del Cristianismo. Buenos Aires, Paidos, 2005

${ }^{5}$ Korstanje M. "El Ocaso de la Imaginación, una aproximación etno-filosófica del miedo a los viajes". Thémata. Revista de Filosofía. Num. 41, pp. 197-223
} 
Creed. El principio del ateismo comienza con la imprenta y la inventiva de Gutemberg para trasladar a papel algo tan simple pero no por ello menos profundo como las ideas. Hasta el momento, la Iglesia centralizaba y monopolizaba la construcción pensamiento por medios de los libros. La imprenta permite diseminar a una gran velocidad y reproducir diferentes textos fuera de la hegemonía católica. Si bien es cierto, los emperadores disputaban poder junto a los funcionarios eclesiásticos, la realidad era que en la Edad Media no se cuestionaba ni la existencia de Dios ni la influencia de sus representantes en la tierra. No ha sido hasta después de la reforma protestante encabezada por $M$ Lutero que los dogmas de la Iglesia Católica comienzan a desmoronarse. La interpretación de la Biblia comienza no solo a ser cuestionada por la Reforma sino por otros movimientos que le siguieron como ser el nacimiento de la "Ciencia" moderna la cual por medio de la biología, antropología y geología ponían en tela de juicio el contenido de los textos sagrados. La religión, que al principio veía a la racionalidad con buenos ojos, comenzó a debilitarse por dentro hasta que finalmente fue carcomida por la Ciencia y la modernidad ${ }^{6}$. R. Castel no se equivoca cuando aduce que el retraimiento de la caridad cristiana fue la base para el advenimiento del temor. El hombre busca una zona de "cohesión" para resguardarse del riesgo que representa su existencia. Desde las sociedades pre-industriales hasta las post-industriales, se asiste a un cambio radical en la forma de concebir el trabajo. Se parte de una vulnerabilidad dada por exceso de coacciones que finalmente sucumbe frente a un debilitamiento progresivo de las diferentes protecciones. Para el hombre, lo social se encuentra como mediador entre el trabajo y el mercado. En la edad media, los vínculos estaban dados por linaje, parentesco y coexistencia física (proximidad). Por el contrario, los riesgos estaban dados por el accidente de quedar huérfanos o aislados del sistema de protecciones de la sociedad feudal (riesgo de desafiliación) ${ }^{7}$.

No obstante, el sistema social reacomoda sus desajustes localizando al huérfano dentro de una familia más extensa (familia providencial) funcionando como verdaderos sistemas orgánicos integrados. Si bien estas sociedades, estaban completamente expuesta a grandes catástrofes, miserias y guerras, su forma de adaptación generaba seguridad en sus miembros. La protección estaba condicionada a la interacción y el aislamiento significaba la muerte del sujeto. Este tipo de sociedades no son móviles pero son eficaces frente a la "desafiliación". La asistencia nace como el primer intento feudal de protección por cercanía y para ello era necesario que el sujeto tuviera un domicilio fijo. En el siglo XIV la peste negra y los diversos cambios demográficos que ella generó, causaron una merma en la fuerza de trabajo (brazos) y un aumento en la oferta. En busca de mejores condiciones miles de campesinos comenzaron una movilidad que las estructuras políticas y eclesiásticas intentaron prohibir, surgen así los primeros atisbos de

\footnotetext{
${ }^{6}$ Turner, J. Without God, Without Creed. The origin of unbelief in America. Baltimore, The John Hopkins University Press, 1986.

7 Castel, R. La Metamorfósis de la Cuestión Social. Una crónica del salariado. Buenos Aires, Paidos, 1997.
} 
movilidad en la Edad Media en donde el trabajo tradicional y vocacional comienza a ceder paso a una especie de cambio de paradigma.

El vagabundo en tanto que símbolos del proceso de desafiliación creciente que implica la modernidad ha sido perseguido, encarcelado y hasta ejecutado históricamente por ser un actor que desafía el orden dado por el pacto social. El constante crecimiento del vagabundeo representa el debilitamiento progresivo del lazo social y las redes de sustentabilidad para proteger al sistema productivo. El vagabundo no solo no poseía una profesión fija sino representaba un peligro para la mayoría de las personas. La movilidad estaba supeditada a una necesidad de desplazamiento en busca de oportunidades. La imagen negativa del vagabundo se corresponde con una construcción cultural que obedece a un manejo político. Su condena hablaba más de la imposibilidad de transformar la situación que de su verdadera peligrosidad para el sistema. El rastreo histórico de Castel advierte que este proceso no se detendrá hasta el inicio la modernidad liberal. Los gremios formados alrededor de la profesión y de la protección del maestro dan lugar a una nueva forma de acumular ganancias y de transformación de la empresa por medio de un discurso "corporativista" que intenta ser controlado y reprimido por el Estado a cualquier costo.

La necesidad de que "otro" trabaje para el maestro y que ese mandato sea voluntariamente obedecido, es, sin lugar a dudas, la base ideológica del capitalismo comercial pre-industrial, admite el profesor Castel. En esta época, la ganancia ya no está con quien produce sino con quien comercia. El liberalismo no pudo ser posible antes del siglo XVIII por varios motivos, entre los más importantes se encuentran: la idea de acceder al trabajo libre sin las ataduras de los gremios, la afluencia de más capital que trascendía los límites feudales, la caridad celosa sede su espacio a la formación de una nueva clase: el proletariado. De esta manera, la afluencia de capital acelera el proceso de individualización en donde las antiguas instituciones se ven incapaces de proteger a los individuos generando un estadio irreversible de fragmentación social. La percepción (inflación) moderna de los riesgos se corresponde con una tendencia de "liberalización" de la economía asociada a un aumento en las vulnerabilidades del trabajador. La paradoja radica en que el trabajador, aunque menos vulnerable de hecho, se percibe en constante peligro.

Las antiguas instituciones de caridad comenzaron a verse como escollos para el progreso y la libertad del trabajo: "la libertad de trabajo debe liberar también la iniciativa privada, el gusto por riesgo y el esfuerzo, el sentido de la competencia. El deseo de mejorar la propia condición es un motor del que la industria no puede prescindir. Se está en las antípodas de la concepción tradicional, para la cual la norma social consiste en inscribirse en un orden fijo y quedar satisfecho. Es total la ruptura con la sociedad de órdenes, de estatutos, de estados, regida por las tutelas". El mercado para esta ideología se presenta como el único capaz de lograr cohesión entre los individuos.

${ }^{8}$ Op. Cit. 177 
Con el advenimiento del mercado liberal y la anglo-democracia, los hombres experimentaron una nueva forma de expansión ya no aquella que exploraba los confines del universo como dijera Arendt, sino una muy diferente orientada al centro del hombre mismo, a su necedad y narcisismo ${ }^{9}$. En este sentido, C. Lasch afirma el miedo se ha convertido, en los últimos años, en un fenómeno que ocupa la atención de la psiquiatría y la psicología como un indicador patológico de malestar el cual impide el buen funcionamiento del "hombre-maquina". Principalmente vinculado a una culpa no resuelta, trauma, o síntoma de estrés, estos "charlatanes" enfatizan en la superación personal, en el temor como una barrera extrema al quehacer diario, y en la regulación de la propia auto-estima. A medida que más libros se escriben sobre ataques de pánico o brotes fóbicos, mayores son los temores en la sociedad contemporánea. La introspección y la sobre-protección de los niños son aspectos funcionales al narcisismo. Existe una tendencia, casi irreversible, a concebir el mundo externo como peligroso, catastrófico y caótico. Dicha tendencia es producto de un cambio de valores y cosmovisiones que aparecieron por vez primera con la modernidad. Ya nadie busca una solución a los problemas que pueden llevar a la catástrofe, sino que enfatizan en la supervivencia individual. A la cultura narcisista, que caracteriza la vida en nuestra sociedad, le cuesta comprender el futuro, en parte a su desinterés por el pasado pero por sobre todo por la falta de tradición.

El pasado sólo representa para la cultura narcisista una trivial forma de comercialización e intercambio (ver patrimonialización cultural). En tanto que, el miedo se ha convertido en un valuarte de los "terapeutas" (como si fueran los únicos autorizados a examinar el fenómeno), el sujeto moderno ha subordinado todas sus habilidades a la "empresa" siendo incapaz de satisfacer sus propias necesidades, incluso el cuidado de los hijos. En el quehacer de la vida diaria, el sujeto es separado del seno familiar para ser reconducido hacia el trabajo. El tiempo consumido como ente de trabajo no le permite estar al cuidado de sus hijos y seres queridos, servicio que traslada en jardines maternales, institutrices y tutores. De esta forma, el abandono de sí y de otros se replica de generación en generación exacerbando el carácter narcisista. En perspectiva, lo cierto es el hombre se ha convertido, en igualdad completa a otros hombres, en materia prima, bien consumible y consumidor del mercado moderno. A diferencia de otros autores que hablan del declive del Estado, Lasch prefiere afirmar que el sujeto se ha convertido en dependiente del Estado y de las grandes corporaciones. El narcisismo, como patología social, refleja esa dependencia ya que obliga al ciudadano a no poder vivir sin la aceptación de otros (imagen grandiosa del self). La liberación del apego a la familia y a los lazos sociales contribuye a que el narcisista alimente su imagen desmesurada, pero a un alto costo, el aumento sistemático de la inseguridad ${ }^{10}$.

\footnotetext{
${ }_{9}^{9}$ Arendt, H. La Condición Humana. Buenos Aires, Paidos, 1998.

${ }^{10}$ Lasch, C. La Cultura Narcisista. Santiago de Chile, Andrés Bello Editorial, 1999
} 
La realización personal se ha encaminado como el valuarte máximo de la sociedad narcisista. Existe toda una crítica cultural que opina la terapia psicológica tiende a adoctrinar a las clases bajas en metas e intereses propios de las "altas" como el desarrollo personal, y el auto-control. No obstante, Lasch considera a estas posturas como reduccionistas. Las cuestiones de vacío interior y terror no nacen como resultado de la vida interna, sino como producto de cuestiones psicosociales ancladas en el capitalismo moderno. El papel de la desconfianza y la incertidumbre serían en términos de Lasch resultado de la falta de futuro y privatismo. "Nuestra sociedad, lejos de promover la vida privada a expensas de la pública, ha hecho que sea cada vez más difícil hacer amigos, lograr encuentros amorosos y matrimonios profundos y duraderos. A medida que la vida social se torna cada vez más belicosa y más bárbara, las relaciones interpersonales, que sin duda ofrecen un alivio ante esas circunstancias, adoptan las características de una lucha. Algunas de las nuevas terapias dignifican esta lucha con los términos de asertividad y lugar limpio en el Amor y el matrimonio" ${ }^{11 .}$

En otras palabras, el desatino de los profesionales de la salud (psicólogos) y analistas con respecto al vaciamiento del self no solo radica en su incomprensión sino en la privatización, o mejor dicho individuación de su causa social. Se hace demasiado foco en el individuo como causa de algo que en realidad se presenta como ajeno a éste pero que condiciona su comportamiento. Para Lasch es necesario adentrarse en el génesis de la "personalidad narcisista" de nuestros tiempo. El narcisismo es parte de la desintegración social. Los limites del super-yo social tienden a desmoronarse, y el ego individual no encuentra barreras o limitaciones a su deseo. Existe una tendencia teórica equivocada iniciada por $\mathrm{E}$. Fromm en identificar al narcisismo con todo lo vinculado al egoísmo, y la glorificación del yo, cuando en realidad tiene más que ver con "el odio" hacia símimo. En consecuencia, el narcisismo para estos autores se constituye como metáfora o espejo del yo. Partiendo de la base que la personalidad es el yo socializado en la cultura, Lasch sugiere que el narcisismo opera redirigiendo el amor rechazado hacia el yo en forma de odio. Las necesidades no cubiertas por la madre pueden ser transformadas en fantasías de una "madre" imaginada. Por tal motivo, los pacientes narcisistas "suelen experimentar intensos sentimientos de vacío e in autenticidad. Aunque el narcisista puede funcionar en el mundo y a menudo encantar a otras personas (en no poca medida con el pseudoesclarecimiento de su propia personalidad), su devaluación de los demás, y su falta de curiosidad por ellos, empobrece su vida personal y refuerza la experiencia subjetiva del vacío. Carente de cualquier compromiso intelectual auténtico con el mundo - a pesar de su valoración frecuentemente inflada de sus propias habilidades intelectuales-, exhibe escasa capacidad para la sublimación. Por lo tanto depende de otros, de quienes requiere infusiones constantes de aprobación y admiración. Debe asociarse con alguien, vivir una existencia emocional, junto a su aproximación manipuladora, explotadora de las relaciones interpersonales, hace que esos vínculos resulten blandos, superficiales y profundamente

\footnotetext{
${ }^{11}$ Op. Cit. 51-52
} 
insatisfactorios “12. Las imágenes malas del exterior lo tienen totalmente preocupado por la salud individual, casi hasta un punto hipocondríaco. El narcisista vive con un constante sentimiento de superioridad. La necesidad de admiración y superioridad son contrarias al envejecimiento. Quienes dependen de la autoafirmación por medio de la belleza, la juventud, fama o encanto de cualquier tipo se ven seriamente amenazados por el paso del tiempo.

La gente ordinaria ya no sueña con atravesar caminos plagados de obstáculos, sino simplemente con sobrevivir a esas amenazas y en su ficcionalización se encuentra el grado de admiración que el ego narcisista necesita. La corrosión económica y la inestabilidad laboral han provocado que el sujeto de rienda suelta a sus deseos hedonistas en un presente mediato. El día se vive como consecuencia de una falta constante de normas y reglas fijas (es decir, de ley). La ética protestante que vinculara al trabajo con la frugalidad, la creatividad, el autocontrol y el progreso ha dado paso a una nueva ética de la auto-conservación. La primera noción de socialiabilidad que impregnaba la moral puritana, dio lugar finalmente al avance del privatismo a la vez que el progreso comenzó a depender de la "voluntad de poder" y la confianza en uno mismo.

\section{III}

El mundo sensible comienza luego del accidente, de aquello que aun cuando no es esperado no solo sucede sino también cambia nuestra posición en ese mundo, nuevo. En la actualidad, podemos ver como diversas compañías de celulares ponen en marcha promociones donde los usuarios acceden a mensajes gratis; dichos mensajes dicen "he llegado bien" o "llegamos bien al hogar". ¿Pero de donde a donde hay que llegar?, o desde ¿donde partimos?. Para responder estas preguntas es necesario mencionar que "todo" viaje encierra una dicotomía insalvable, la atracción y el rechazo a lo desconocido. El viaje, en tanto, motivado por un objetivo (negocios, exploración y simplemente descanso) se encuentra condicionado por la curiosidad y la incertidumbre. Mientras la primera genera atracción, la segunda se refiere a un rechazo manifiesto. Salir del ámbito residencial y de las normas que nos dan seguridad nos pone cara a cara con nuestros propios miedos y angustias, simplemente porque perdemos el control de la situación. La espectacularidad del accidente, no está dada, por sus efectos (de hecho mueren más personas en accidentes viales que en los aéreos, pero los últimos son más temidos), sino por el grado de previsibilidad de la acción. El hombre puede, a diferencia de los animales, imaginarse el desenlace de tal o cual acción y en ese imaginar-con, intenta controlar su propio destino.

En una sociedad post-capitalista, donde el seguro domina las relaciones humanas, el riesgo (como forma estereotipada del miedo) se transforma en el requisito primordial y funcional de las formas modernas de producción. Todos, casi sin

\footnotetext{
${ }^{12}$ Op. Cit 62-63.
} 
excepción, tememos en mayor o menor medida al viaje porque éste nos conduce más allá de nuestras certidumbres. Las sociedades nómadas que exploraban el terreno no tenían ese problema, el temor al viaje comienza sin lugar a dudas, con el asentamiento y la muralla de las grandes ciudades. Diversas crónicas, desde la antigüedad a hoy, hablan (en diferentes culturas) de viajeros que al atravesar un territorio toman contacto con espíritus o demonios los cuales los enferman ${ }^{13}$. Dichos testimonios, hablan, a grandes rasgos de este miedo arcaico que excede nuestro tratamiento como occidentales (tipificado solamente como riesgo). El viaje encierra la construcción de otro que bajo principio de hospitalidad nos deja temporalmente la puerta abierta. A esa observación, Frazer la llamo "tabú al extranjero"14. El temor a viajar parece ser tan arcaico como la hospitalidad misma. Sin lugar a dudas, la serie Lost explora los confines de este miedo al accidente tan presente en nuestra sociedad occidental. En la era del GPS parece que nuestro mayor temor es perdernos (be lost).

Dado el argumento anterior, uno inferiría que el turismo se constituye como tal en tanto que regreso exitoso (de ese cazador original antiguo) al hogar. Si el prestigio está dado sólo para aquellos quienes se adentren a lo desconocido, este es de hecho conferido cuando el regreso se asocia al éxito; es decir, que los héroes se hacen como tales en cuanto a que pueden regresar a su propio hogar. A este principio antropológico (tan presente en casi todas las mitologías) lo denominaremos, principio de "heroicidad". Los sujetos quieren ser especiales y respetados por sus semejantes. La movilidad no cambia nuestra identidad pero si lo hace el retorno. El segundo principio por el cual el turismo se hace posible se refiere a nuestra posibilidad de alejarnos temporalmente de las normas que han dado origen a nuestra sociedad. En este sentido, el principio de "trascendencia" es aquel que lleva a los hombres a moverse física e intelectualmente hacia lo desconocido. Mientras el principio de trascendencia, anclado en nuestra curiosidad, nos lleva hacia delante el de heroicidad requiere nuestro retorno. Sin dicha combinación, el hombre se movería (como el migrante) por necesidad y estaría siempre abandonando su propio hogar. La libertad (o la falta de ella cuando se comete un crimen) es un resultado del principio de trascendencia.

Las tribus nómadas, precisamente tienen el principio de transcendencia más desarrollado que las tribus sedentarias. El temor en el ser-turista se constituye como tal en la convergencia de la trascendencia y la heroicidad ${ }^{15}$. La seguridad del ser-turista (que sólo puede ser tal cuando viaja) se encuentra garantizada por el Estado anfitrión el cual, dicho sea de paso, tiene sus propias reglas. El turista, una vez que acepta ser hospitalizado, debe someterse a nuevas reglas. En

\footnotetext{
13 Albó, X. "La Experiencia Religiosa Aymará". En Rostros Indios de Dios, cuadernos de investigación. La Paz, CIPCA, UCB, 1992.

${ }^{14}$ Frazer, J. G. The Golden bough. Bogotá, Fondo de Cultura Económica, 1993. -

Goody, J. Cocina, Cousine y Clase: estudio de sociología comparada. Barcelona, Gedisa, 1995. Derrida, J. La Hospitalidad. Buenos Aires, Ediciones de la Flor, 2006.

${ }^{15}$ Korstanje, M. "Filosofía del Desplazamiento: un enfoque comparativo entre lógica formal y la crítica de la razón Pura en Kant”. Dilema : revista de filosofía. Vol 12 (2): 69-93, 2008.
} 
ocasiones, esta supuesta hospitalidad se transforma en su contralor, la hostilidad (etimológicamente la palabra hospitalidad y hostilidad tienen misma raíz ospes, que significa lo que es del amo). Cuando eso sucede, el ser-turista es vulnerado en su confianza ante un Estado que no puede brindarle protección. Si bien, cabe aclarar, el Estado es posible gracias al principio auto-administrado de seguridad en un sentido foucaultiano clásico; ello quiere decir, el propio principio de propiedad que mueve la cadena productiva y en consecuencia posibilita el nacimiento del Estado actúa disfuncionalmente por medio del crimen para darle valor a esas mercancías producidas. En otras palabras, el crimen como infería Durkheim, no es ajeno a la sociedad, es un proceso social que lleva a la misma a respetar sus propias normas. El valor de la mercancía se encuentra filosóficamente determinado por la posibilidad y probabilidad de ser expropiada. Por tanto, todo crimen expiado por la falta de libertad (trascendencia) corta la hospitalidad, la suspende anulando la autoridad del estado por la del mercado. Cuando robamos, herimos o matamos no solo anulamos el derecho de ese otro, sino que le damos más valor a la producción económica; ese bien obtiene un mayor valor porque simplemente es codiciado, en cuanto más codiciado mayor es su valor. Esa parece ser la razón por la cual el mercado, en materia de seguridad, parece cada día anular más y más a las fuerzas de seguridad y al mismo Estado. El turismo, por ser resultado de la complejización productiva, anula o dificulta la protección del estado. Si no viajar es la seguridad-absoluta, como es en el caso de los agora-fóbicos, hacerlo abre la puerta a la vulnerabilidad.

No obstante, el ser-turista (ajeno al medio) voluntariamente acepta respetar las normas que paradójicamente lo vulneran en su propia seguridad ontológica. Empero sin ese "desarme voluntario, el turista no podría regresar a su patria y evocar el principio de heroicidad que le da su razón de ser. Su credibilidad se ve mejorada, simplemente, porque él o ella han estado allí mientras el resto es movido a visitar esa tierra para constatar esa narrativa. Claro que la profesionalización ha llevado a lo largo del tiempo a aislar los riesgos propios del viaje y plasmarlo en dos instituciones importantes, el agente de viajes (asesor y proveedor de seguridad) y el viaje (todo incluido). En la medida en que, el principio de heroicidad se hace más fuerte, una mayor cantidad de ciudadanos acuden al turismo como forma de distinción. Paradójicamente, la estandarización del turismo evoca su propia dinámica de exclusividad. Es decir, sí un viajero retorna a su hogar relatando aventuras fantásticas en una tierra desconocida, este hecho atraerá a un segundo, tercer y cuarto viajero. A medida que este proceso se vaya extendiendo y una mayor cantidad de personas viajen, la exclusividad será cada vez menor, mas reducida. La "paradoja del turismo" radica en la siguiente relación filosófica: la exclusividad que genera el desplazamiento se encuentra condenada a la masividad para la reconversión en una nueva exclusividad. El ciclo no solo que nunca se corta, sino que también hace factible la construcción del ser-turista. En tal sentido, es necesario no perder de vista que el temor-al-accidente no constriñe el viaje sino que lo promueve.

El vuelo de Oceanic 815 no solo significó el inicio de la serie Lost la cual cautivó a un millar de televidentes por varias temporadas, sino además ha sentado las 
bases para el debate filosófico sobre temas vinculados a la determinación, la libertad, el accidente y por supuesto el temor. Como afirma bien S. Kaye, Lost simboliza todos nuestros miedos arcaicos, a saber la posibilidad que todo nuestro mundo cambie radicalmente fuera de nuestro propio control. En palabras de la editora del libro La Filosofía de Lost: "la exitosa serie de cadena de televisión norteamericana $A B C$, Lost, habla de ese miedo profundo: el de ser arrancado de todo aquello que conocemos y amamos, librados a nuestra suerte en una tierra desconocida. Este miedo es un miedo filosófico porque refiere a la condición humana. $Y$ nos fuerza a confrontar cuestiones profundas acerca de nosotros mismos y el mundo"16.

El discurso de LOST apela a cuatro pilares fundamentales, Love (amor significando la relación filial), $\mathrm{O}$ (Origen para el sentido humano de la libertad), $\mathrm{S}$ (de supervivencia) y T (de transformación). Lost, como la vida misma, comienza con un accidente del cual los pasajeros (turistas) del vuelo Oceanic 815 se dirimen entre morir o sobrevivir en un ambiente que le es hostil. La particularidad se debe a que "todo vuelo" se presenta como ajeno a nuestra posibilidad de control, y por ende, sujeto a la catástrofe. En este sentido, S. Lee utiliza la posición moral kirkegaardiana para afirmar que la racionalidad asume que toda causa tiene un propósito. Cuando Desmond explica a Locke que el botón de la escotilla debe ser apretado cada 108 minutos, las reacciones son bien diferentes. Mientras Locke decide creer hasta llegar a hacer un culto del "botón", Jack descree.

El accidente, según Desmond, del vuelo 815 fue causado porque éste último olvidó presionar el botón. Parafraseando a Kierkegaard, Lee dice que cualquier "salto de fe" requiere precisamente que hagamos lo que sentimos, sin estar condicionados por el medio cultural. Empero, no deja de ser menos cierto que la determinación (basada en el principio de predestinación) nos exime de cualquier responsabilidad moral por nuestras omisiones. La explicación sucede a cualquier accidente hasta el punto de satisfacer el sentido de los eventos, cuando eso no sucede, sobreviene el terror ${ }^{17}$. Siguiendo este razonamiento, es necesario destacar que toda decisión puede ser concebida como determinada a una consecuencia o azarosa en sus efectos. La comprensión y previsión de los efectos, como proceso antropológico de control, explica las diferentes construcciones que existen frente al infortunio.

Girard y Meulemans sugieren que el accidente concentra pasado y presente de una persona conduciéndola hacia nuevas situaciones fuera del contexto familiar de forma temporal. Este cambio, en el caso de la isla, puede ser comprendido como una nueva oportunidad (transformación) en un segundo "estado de naturaleza". Aquí se da la contradicción entre cambio y repetición; la tesis de la segunda naturaleza enfatiza en la probabilidad en que nuestras prácticas nos

\footnotetext{
${ }^{16}$ Kaye, S. "Introducción: L.O.S.T en Lost". En La Filosofía de Lost: la isla tiene sus razones. S. M. Kaye (Editora), Buenos Aires, El Zorzal, 2010, pp. 11.

${ }^{17}$ Lee, S. "Sentido y Libertad en la isla". En La Filosofía de Lost: la isla tiene sus razones. S. M. Kaye (Editora), Buenos Aires, El Zorzal, 2010, pp. 55-70.
} 
definan como sujetos. Dadas las condiciones, entonces, los personajes se comportan de la misma forma que lo hacían antes del accidente. La liberación parece ser en estos términos sólo parcial. El discurso de la serie Lost encierra la dicotomía del libre albedrío y el fracaso al cambio ${ }^{18}$. Ahora bien, la serie se encuentra, como la mayoría de las narrativas post-modernas, codificada al punto que al espectador le cuesta comprender la trama. Lo que Lost intenta es explotar comercialmente un tipo de código basado en el misterio pero que determinan un varias formas de sentir lo moral en cuanto a las situaciones de nuestro día a día 19. Este tema, también abordado por otros autores nos lleva a un relativismo moral en donde el discurso del emisor es suficiente para definir lo que ésta bien o mal. Dicho relativismo se presenta como necesario en un momento del proceso económico mundial donde la "utilidad" y el "instrumentalismo" dominan la vida cotidiana, es decir, donde se busca todo el tiempo el cálculo racional de los efectos. En este punto Arp y Brace no se equivocan cuando afirman que en Lost las relaciones sociales y la construcción del otro están objetivadas a los propios intereses de cada actor ${ }^{20}$. En este sentido, Sandra Bonetto enfatiza en la frase de Sartre "el infierno son los otros" para explicar como la razón del accidente confina y reúne a los sobrevivientes del vuelo 815. Las condiciones son claras, no pueden escapar física o psíquicamente ni de la isla ni de su pasado (principio de expiación). Siguiendo las contribuciones de J. P. Sartre, Bonetto explica que tenemos una tendencia a objetivar al otro, mientras ese otro posee la misma tendencia. De la convergencia entre las dos voluntades surge el conflicto. En consecuencia, podemos caer en el masoquismo (subordinar mi ego a la voluntad del amo en busca de reconocimiento), el sadismo (someter al otro) o indiferencia (anular completamente la presencia del otro y despertar la obsesión por él). Desde esta visión, el chivo expiatorio es más que imposibilidad el temor a la condición humana de la propia consciencia ${ }^{21}$.

K. Gaffney afirma que "identificar a alguien como otro es identificar a esa persona como marcada de alguna manera, por el color de la piel, la religión, el lenguaje, el género, la orientación sexual o cualquier otra categoría de diferencia que se usa en nuestra cultura para dividir a la gente. Marcar a alguien como otro indica una relación de poder, porque tiene el poder de identificar a cualquiera como otro es

\footnotetext{
${ }^{18}$ Girard, C. y Meulemans, D. "La Isla como prueba del libre albedrío: libertad de reinvención y determinismo interior en Lost". En La Filosofía de Lost: la isla tiene sus razones. S. M. Kaye (Editora), Buenos Aires, El Zorzal, 2010, pp. 83-96.

${ }^{19}$ Grimwood, T. "Lost Codificado: interpretación y deconstrucción en la narrativa de Lost". En La Filosofía de Lost: la isla tiene sus razones. S. M. Kaye (Editora), Buenos Aires, El Zorzal, pp 97110, 2010.

${ }^{20}$ Austin, M. “¿Qué les deben Jack y Locke a sus padres?. En La Filosofía de Lost: la isla tiene sus razones. S. M. Kaye (Editora), Buenos Aires, El Zorzal, 2010, pp 17-26 - Arp, R. y Brace, P. "Tregua Moral: objetivación en Lost". En La Filosofía de Lost: la isla tiene sus razones. S. M. Kaye (Editora), Buenos Aires, El Zorzal, 2010, pp 27-40 - Wrisley, G. (2010). "La Isla del Subjetivismo Ético: no el paraíso de Lost". En La Filosofía de Lost: la isla tiene sus razones. S. M. Kaye (Editora), Buenos Aires, El Zorzal, 2010, pp. 41-54.

${ }^{21}$ Bonneto, S. "Sin Salida ... de la isla: un análisis sartreano de Lost". En La Filosofía de Lost: la isla tiene sus razones. S. M. Kaye (Editora), Buenos Aires, El Zorzal, 2010, pp 111-122.
} 
por definición alguien normativo, no-otro y sin marca. Percibir a alguien como otro es un proceso que identifica a esa persona como inferior"22.

Por demás interesante es la relación entre pericia y riesgo. El cine de terror ha históricamente resaltado esta dicotomía donde el turista es siempre la primera víctima de los villanos. Por ejemplo, en el consagrado y clásico Tiburón el especialista acude al intendente del pueblo para pedirle que posponga la temporada turística ya que un enorme tiburón blanco acosa las costas. El escualo no reconoce la vulnerabilidad del turista, simplemente lo destroza y devora. Pero el intendente, portador de autoridad, decide no mover la temporada influenciado por motivos puramente económicos. El mensaje, a grandes rasgos, es que la negatividad del turismo se encuentra fundamentada por su raíz económica la cual paradójicamente evoca su vulnerabilidad. En otros filmes como Masacre en Texas, Los Extraños, o The Hills have eyes, los villanos son mutantes (mineros o residentes locales) que descuartizan sádicamente a indefensos turistas que visitan la zona sin saber lo que les espera (contingencia). El malo no tiene una razón lo hace simplemente por placer. Lejos de un estado presenta para dar seguridad, estas familias o grupo de amigos buscan distensión (heroicidad) pero encuentran la negación misma de toda hospitalidad. Misma relación puede hacerse en los polémicos Films, Hostel I y II donde bellos jóvenes turistas (inicialmente seducidos/as por prostitutas) son secuestrados en Eslovaquia para ser horriblemente torturados hasta morir. Lo económico, es decir el pago del servicio, hace posible dicho acto. Por otro lado, es importante mencionar que producto de su propio hedonismo, las víctimas son vejadas por otros turistas (millonarios psicópatas) que se transforman en cazadores de sus presas. El discurso del terror puede ser analizado siguiendo el siguiente esquema:

1) Los turistas se alejan de la civilización y del poder del Estado acrecentando su vulnerabilidad.

2) Las víctimas son jóvenes o niños, por lo que se asume, el terror evoca la imposibilidad de la vida, es decir, si se nos enseña que el paso del tiempo es el principal verdugo (morir de viejo), la muerte de los jóvenes articula una contradicción (tabú) el cual es descrito como el "temor fundante" de toda sociedad. 3) Los villanos están deformados por acción de la radiactividad u otro motivo. Su raíz maligna, de todos modos, trasciende su estética para centrarse en su ética. A la sociedad moderna la falta de moral, es la negación de hospitalidad para con el más débil (el ser turista). La otredad, construida etnocéntricamente, evoca terror.

4)

5) representa ser estadounidense en el extranjero. Codiciado por ser portador de

\footnotetext{
${ }^{22}$ Gaffney, K. "Vienen los otros: ideología y otredad en Lost". En S. Kaye. La Filosofía de Lost: la isla tiene sus razones. Buenos Aires, Libros del Zorzal, 2010, pp.123-136.
} 
civilidad, y odiado por las políticas de su país, existe un discurso moderno a considerar "a todo extranjero como peligroso".

6) El sexo, la belleza, la comida, son elementos importantes a la hora de definir la hospitalidad. Empero, muchos de estos filmes advierten sobre la naturaleza ambigua de la hospitalidad.

7) La vulnerabilidad del turista es mayor cuando entra a un territorio extranjero y se somete a los derechos de otro. En consecuencia podemos afirmar que el terror, tanto en Lost como en la mayoría de las películas de terror, comienza con el villano y culmina porque éste último no respeta el principio de hospitalidad.

8)

Naturalmente, si el hombre confiere sentido a los hechos que suceden para su propia seguridad, la falta de sentido (no tener un porque) en un mundo puramente instrumental es el génesis del mal.

Por último cabe destacar, Lost como serie y su éxito parecen estar concatenadas (más allá de la virtud de los guionistas) en la posibilidad de reflejar los valores más representativos de la vida moderna occidental. Nuestro relativismo moral, nuestra imposibilidad para comprender al otro, la superioridad técnica o razón instrumental que nos lleva a comprender los eventos por relación causa-efecto y el temor surgido a lo que no se puede controlar (la naturaleza) son entre otras cosas valores o aspectos significantes de nuestra propia forma de vivir. La presente nota ha intentado explicar filosóficamente esa eterna contradicción entre trascendencia y heroicidad que constituyen el principio del "ser turista" del cual la literatura especializada aún no se ha ocupado.

\section{IV}

La cuestión de la seguridad ha estado en boga de todos y se ha transformado, en los últimos años, en valuarte del periodismo; pero el mismo no es parte de la solución sino del problema. Desastres naturales, teorías apocalípticas, virus pandémicos, y ataques terroristas se han configurado en un marco simbólico que preocupa pero a la vez entretiene a las audiencias de todo el mundo. En este contexto, la sensibilidad pública parece atada a la inseguridad como la medieval por el miedo al infierno. Dadas estas condiciones, la periodista N. Klein ${ }^{23}$ instala un nuevo término en el estudio de los desastres, asociado a las oportunidades y la flexibilización de las condiciones de trabajo y contratación por las cuales, la economía de los Estados Unidos crea una "doctrina del shock" para implementar políticas que de otra forma serían rechazadas por la ciudadanía. El "capitalismo del desastre", agrega Klein, utiliza el miedo como un efecto dominador sobre la población a quienes el sistema privatizador no les da otra solución más que una promesa de falsa seguridad. Todo estado de crisis permite

${ }^{23}$ Klein, N. La Doctrina del Shock. El Auge del Capitalismo del Desastre. Buenos Aires, Paidos, 2008. 
que se venda "al mejor postor" la infraestructura estatal a manos privadas a la vez que las personas se encuentran entre el trauma y el pánico. En su estado de vulnerabilidad, los sujetos aceptan cuestiones y reformas que de otra forma rechazarían radicalmente. Luego de una minuciosa lectura del libro en cuestión, la tesis de la doctrina del shock es clara a grandes rasgos, toda crisis real o percibida, da lugar a cambios concretos. El capitalismo necesita de escenarios de devastación para construir nuevas estructuras urbanísticas, como el caso de Sri Lanka, donde tras el Tsunami que conmocionara al mundo se levantaron lujosos centros turísticos. Por desgracia, las apreciaciones de Klein no son el fruto de un trabajo científicamente riguroso ni mucho menos de fuentes claras (la mayoría artículos de diarios y periódicos) por lo que su locuaz tesis se ve disminuida. Abiertamente Klein advierete, "durante tres décadas, Friedman y sus discípulos sacaron partido metódicamente de la crisis y los shocks que los demás países sufrían, los equivalentes extranjeros del 11 de Septiembre: el golpe de Pinochet otro 11 de septiembre, en 1973. Lo que sucedió en el año 2001 fue una ideología nacida a la sombra de las universidades norteamericanas y fortalecida en las instituciones política de Washington por fin podía regresar a casa"24.

Para algunos, la posición de Klein es cómoda y anclada en un sentimiento de paranoia por lo que se asume una conspiración mundial del mercado; además, Klein desconoce cuales han sido las fuerzas históricas y sociales que contribuyeron a la creación del libre mercado (sus ataques sólo se remontan al economista liberal M. Friedman pero cabe recordar las raíces del liberalismo vienen de mucho tiempo atrás). No formada académicamente dentro de los claustros universitarios, Klein, no obstante, provee elementos e indicadores que ayudan a comprender como funciona el capitalismo moderno y su necesidad de destrucción cíclica para una nueva creación. Este tema, merece particular atención. Veremos a continuación que el proceso democratizador que da lugar al libre mercado no puede nacer en otro lugar más que en Inglaterra por diversos motivos. Los sociólogos posweberianos, como David Harvey ayudará a comprender mejor el devenir histórico de nuestra época actual.

La modernidad capitalista se aborda por varios flancos pero la mayoría de los autores tienen problemas conceptuales para poder, en primer lugar, describirla con claridad, segundo explicar su devenir histórico. En este sentido, P. Harvey enfatiza en la naturaleza dinámica y multifacética de la posmodernidad desde una perspectiva bastante convincente. Una de las cuestiones más importantes sobre el término es poder llegar a una definición clara, objetivo que hasta el momento no ha podido ser cumplido. La posmodernidad es el capitalismo que denuncia Klein. Existen no solo diferentes acepciones de modernidad y posmodernidad, sino que además lo posmoderno parece diluirse en un cambio anárquico y progresivo. Desde su perspectiva, Harvey considera que la posmodernidad, en tanto, vanguardia estética, ha roto con los ideales de la ilustración sobre lo eterno y lo inmutable para convertirse en "un pastiche" que se mueve bajo una lógica de "destrucción creativa". Para crear nuevas cosas, lo postmoderno avanza

${ }^{24}$ Op. Cit, p. 34 
destruyendo todo a su paso. Pero a su vez, vuelve a destruir lo que había creado retroalimentando un proceso de destrucción, construcción para una nueva destrucción (ambivalencia). Por otro lado, si la llustración propugnaba la idea que el mundo podía ser descrito y controlado sólo sí los hombres aceptaban que todo problema tenía una univoca causa, para la posmodernidad los problemas son multi-causales y su etiología totalmente subjetiva. Ciertamente, el cambio pudo haberse producido, admite Harvey, por el malestar que había provocado la Ilustración y una pérdida de fe "progresiva" en el avance del progreso. La desigualdad de las clases sociales producidas por el avance del capitalismo fue otro factor de quiebre epistémico que asumía la idea que las cuestiones del hombre requerían múltiples respuestas, nace así una especie de relativismo que reemplaza al argumento científico de la Escuela de Viena por una "hegemonía" de las cualidades sensibles del sujeto para comprender la realidad ${ }^{25}$. En consecuencia, no habría un "mundo real" sino varios mundos construidos y presentados como "reales". Se da, en resumen, progresivamente una serie de quiebres y fragmentaciones de saberes que conllevan a una confusión metodológica subordinada a una lógica de consumo capitalista y a una vida social basada en el cálculo racional de los efectos (especulación). Esa incesante incertidumbre e inestabilidad sentaron las bases para el advenimiento de un miedo constante el cual puede observarse en todos los aspectos importantes de la vida en sociedad. Cabe aclarar que el primer modernismo, hasta 1945, fue "heroico" pero atravesado por el "desastre". Posterior a ese proceso, sobrevino un "modernismo alto" en donde se enfatizaban los valores del progreso y la emancipación de la llustración; pero la racionalidad del alto-modernismo dio lugar a una nueva forma estética, el posmodernismo; movimiento por el cual la alineación del hombre-maquina promovida por ciertos sectores artísticos y culturales fue absorbida, elaborada y canalizada por los grupos políticos en una ideología liberal específica. Para tal caso, escribe Harvey, los políticos comienzan a incorporar nociones estéticas creando una ideología oficial que hace de la rebelión no solo su mayor valuarte, sino un fin en sí. La burocracia técnica dio lugar a movimientos anti-modernistas (principios del 60), que generaron una fragmentación de la cultura en varias contra-culturas. Si bien todos estos movimientos, terminaron en un estrepitoso fracaso fueron la precondición para el surgimiento de la postmodernidad y toda la "incoherencia" que trae consigo.

En este punto y para Harvey, el posmodernismo alcanza también una idea de fragmentación pero sin intentar contrarrestarla como sí lo intentaba el modernismo. El posmodernismo parte de varias narrativas todas ellas consumidas dependiendo del contexto del sujeto, sin un lugar de poder fijo sino simplemente transmutable. Si una de las características fundamentales de la modernidad es hablar por los otros pero bajo un único argumento, la posmodernidad enfatizará en que todas las minorías tienen su propio derecho a expresarse y a ser aceptados (concepción pluralista). Los textos narrativos de los actores serían complejos textos y voces que anteceden y destruyen la posibilidad de instaurar cualquier

\footnotetext{
${ }^{25}$ Harvey, P. La Condición de la Posmodernidad: investigación sobre los orígenes del cambio cultural. Buenos Aires, Amorrortu Editores, 2004.
} 
meta-narrativa. Básicamente, el posmodernismo quiere perfilarse como una forma de experimentar y estar en el mundo pero su fragmentación conlleva a un problema psicológico el cual no ha sido observado en otras épocas, el riesgo, la ambigüedad y la incertidumbre. En este sentido, Jameson hace referencia a lo posmoderno como un collage en donde predomina la superficialidad, el impacto "instantáneo" que reverencialmente se sustituyen animismo en el tiempo. El posmodernismo, no sería otra cosa, siguiendo este desarrollo, que una lógica subyacente del capitalismo tardío ${ }^{26}$. Entre tanto el concepto de cultura juega un rol primordial en la configuración de escenarios estéticos, cuyo valor agregado, conllevan a una estimulación en el consumo. Si para Jameson, el quiebre de la modernidad es cultural en D. Harvey es económico. La ruptura entre la posmodernidad con la modernidad nace de la crisis Árabe-Israelí en 1973 que puso en vilo a todo el mundo Occidental por el embargo a las exportaciones de petróleo. Como resultado de un aumento en las fuentes energéticas, el capital existente tuvo que diversificarse hacia el préstamo y una posterior acumulación flexible.

De esta forma, las nuevas económicas de mercado hicieron un fuerte énfasis en el signo como criterio de consumo principal. Si la lógica fordista de montaje exigía a los fabricantes tiradas de productos seriadas, la nueva forma económica se centró en el consumo a medida cuya reacción fue la creación de un capital global y móvil. Los constantes cambios que exige el capital móvil obligan a los consumidores no solo a vivir el día a día sino además a verse envueltos en un clima de constante incertidumbre donde la antigua compresión del espacio-tiempo se ha desdibujado por completo. La ilustración y la crisis de valores que ella despertó obligaron a mirar el mundo por medio de un nuevo prisma, los mapas. De esta manera las crisis subsiguientes del modernismo y posmodernismo empujaron a una nueva concepción de espacio y tiempo. La paradoja central de la posmodernidad, sin lugar a dudas, es cuanto menores son las barreras espaciales para la movilidad individual, mayor es la sensibilidad del capital a los cambios. En consecuencia, el incentivo para reciclar y diferenciar los lugares para atraer flujos de capital es un fenómeno más que interesante para investigar. Existe, adhiere Harvey, una tensión entre centralizar y descentralizar, entre historia y presente, son aspectos importantes para comprender la competencia por la hiper-acumulación; sin más, la tendencia a la patrimonialización de la cultura o a la invención de espacios para el consumo turístico son ejemplos claros de dicho proceso ${ }^{27}$. Como dice Klein, el capitalismo necesita de un proceso de destrucción para edificar su consumo y destruirlo nuevamente para volver a construirlo. El devenir de la desprotección que implica la modernidad ha sido progresivo.

Sin lugar a dudas, una de las mayores falacias del libro de Klein no es por lo que dice, lo cual puede ser ilustrador y veraz, sino por aquello que calla. Al igual que

\footnotetext{
${ }^{26}$ Jameson, F "Postmodernism, or the cultural logic of late Capitalism". New Left Review, 146: 5392, 1984.

${ }^{27}$ Harvey, P. La Condición de la Posmodernidad: investigación sobre los orígenes del cambio cultural. Buenos Aires, Amorrortu Editores, 2004.
} 
muchos intelectuales de incansable fama pero poca rigurosidad científica, Klein considera al capital como una creación azarosa del destino, que en la modernidad actúa soslayando la libertad individual de las personas. Su tratamiento sobre el caso ruso, argentino o chileno dista de ser real, además de los groseros errores de concepto. Recordemos, Klein dice que la URSS cae por la introducción del libre mercado la cual sólo fue posible gracias a la doctrina del desastre. En este punto, toda acción del mercado es anti-democrática por antonomasia y coercitiva. Asimismo, la relación de la CIA con los golpes de estado latinoamericanos lleva a un discurso unívoco en donde no se analizan con claridad las causas reales del terrorismo. Históricamente, la compleja relación entre los grupos golpistas, políticos destituidos y grupos insurgentes no parece ser tan simple como la autora la plantea. Los grupos disidentes obedecían a facciones expatriadas de la política que controlaban la revuelta desde fuera. Uno de los problemas fundamentales de los mal llamados "guerrilleros" latinoamericanos era que no tenía representación política y en consecuencia sus actos estaban prohibidos. Un estado incapaz de mantener el orden y que recurría a la tortura $u$ otros actos ilegales junto a un sentimiento generalizado de paranoia y un grupo de disidentes que se escondían detrás de la población para perpetrar sus ataques, dieron como resultado lo que Klein llama el estadio de Shock. Si bien puede ser cierto pero harto improbable la participación de la CIA, en estos procesos, lo importante es que el terrorismo es una relación dialéctica entre dos o varios actores y no sólo patrimonio de uno. El "terrorismo de Estado", término falaces si los hay, parece ser uno de los caballitos de batalla de Klein.

En tanto que manipulación política que engendra desestabilización de una región o ciudad con fines tan diversos que es difícil clasificar al terrorismo; empero la mayoría de los procesos (con mayor o menor virulencia) se corresponden con tres facetas: a) formación, b) expansión y desestabilización y c) retracción. En la primera fase, los insurgentes reivindican una causa y se invisibilizan (es decir se desterritorializan muchos de ellos auto-declarándose clandestinos) para luego saltar a la expansión la cual no es otra cosa que un ataque sistemático a ciertos grupos considerados como vulnerables; la víctima de estos ataques no sabe el destino que le depara. Más allá de la monstruosidad de estos actos, el fin es disuadir al Estado en términos de escuchar las demandas. Debido a que el Estado no tiene control de la situación recurre a la tortura como método utilitarista para frenar el próximo ataque; empero la técnica de tortura tiene una particularidad, nunca es efectiva, por al sencilla razón que "quien está involucrado en los ataques prefiere morir sin hablar" y quien habla es una persona que no está familiarizada con ellos pero lo hace porque "no soporta el dolor"; este último escenario por desgracia lleva a nuevos "inocentes" hasta el punto de multiplicar la tortura por doquier. No obstante, la presión y el poder represivo del estado son tan grandes, que en una última fase, el grupo insurgente es diezmado y debe retraerse pero eso no sugiere su total desaparición.

En consecuencia, el terrorismo debe comprenderse como una respuesta, no a la modernidad ni a la doctrina neo-liberal, sino al imperialismo. En una etapa inicial, las élites locales, promotoras ideológicamente de los grupos rebeldes, mantienen 
una relación de "amistad" y cooperación con los imperios, pero una vez "rotas esas relaciones" (ya sea por retraimiento del Imperio, desestabilización económica o simplemente por desengaño), nace el discurso del "odio" que guía (tanto de un lado como del otro) a la matriz "terrorista". Además dicho sea de paso, los grupos rebeldes por regla general siguen patrones pscio-sociales de representación místico-religiosa aún cuando se presenten como seculares. En este sentido, AlQaeda, Montoneros, ERP, Sendero Luminoso y Hamas tienen puntos importantes de discordancia pero mucho en común: el espíritu "paranoico" que responde a una imposibilidad manifiesta del yo para romper con la dependencia externa. Pero su lucha parte de una ausencia, Al-Qaeda lucha en nombre del profeta Mahoma quien se cree ascendió a los cielos en cuerpo, Montoneros en nombre de Perón físicamente en España, y ERP de Lenín. Enarbolando los valores y banderas de héroes ausentes, sus enemigos se presentan siempre "como potencias" o "entidades" más grandes, fuertes, poderosas, corruptas, malignas e incontrolables que hablan de una situación previa de sumisión. El paranoico o "manía persecutoria", necesita, estar sometido y comprender el mundo que lo rodea. Su complejidad lo asusta, y la conspiración le da sustento a su vida, y orden al caos. El terrorismo como filosofía no desaparece con el estado derecho sino que muy bien puede mantenerse solapado por años; incluso en la vida democrática. El pensamiento paranoide es incorregible y toda evidencia contraria es llevada para reconfirmar el postulado inicial, hecho por el cual algunos especialistas sugieren que dar a estos actores representación política es una forma de mitigar los efectos más negativos de la clandestinidad. La persecución (en todas sus formas) sólo alimenta la fuerza del espíritu paranoide y sienta las bases para el advenimiento del terrorismo. El espíritu "del terror" no es monopolio de un grupo sino que nutre tanto a políticos o gobernantes, como a intelectuales, empresarios, religiosos, escritores, etc.

Siguiendo este razonamiento, Klein sugiere erróneamente que la doctrina del shock fue originalmente acuñada en las dictaduras latinoamericanas de los 70 . Como bien hemos explicado en el siguiente trabajo, la democracia anglosajona, el libre mercado, el capital y sus efectos sobre la percepción humana son producto del mismo proceso. A propósito, T. Eagleton llama la atención sobre el cinismo de ciertos intelectuales que atacan la superficialidad del posmodernismo, (efectos del capital) pero sin reparar en sus raíces o causas principales (el liberalismo democrático), como ser el flujo del capital y su alta movilidad. La ilusión o el poder de la ideología no radican tanto en lo que se dice o se permite ver, sino precisamente en aquello que se silencia pero sigue soslayadamente tan presente en nuestra vida que no atinamos a notar. Las criticas de los jóvenes a los ideales de ilustración no solo serían infundados sino recubiertos de una gran duda, la paradoja, explica Eagleton es que los jóvenes disidentes que piensan saberlo todo sobre Foucault, realmente no piensan lo que creen que piensan. De esta forma, en el posmodernismo se puede hablar de todo y a la vez de nada. Se puede tocar el tema de la cultura humana pero no de la naturaleza humana, de género pero no de clase, de postcolonialismo pero no de burguesía. El posmodernismo ha desafiado y puesto al descubierto a la mayoría de las instituciones de forma que si todas las convenciones son arbitrarias, las prácticas sociales deben estar 
circunscriptas a cierto individualismo. Lo material ha dado lugar a la hegemonía del dinero y del signo por el cual se crea más dinero dando rienda suelta a los placeres y el determinismo reduccionista del libertinaje ${ }^{28}$. "El poder del capital es ahora tan terriblemente familiar, tan sublimemente omnipotente y omnipresente que incluso vastos sectores de la izquierda han logrado naturalizarlo, tomándolo por garantizado como una estructura tan inconmovible que es como si apenas tuvieran coraje para hablar de él" ${ }^{29}$. El mercado mueve una fuerza anti-elitista que nivela toda distinción bajo un uso de igual jerarquía abstracto como el dinero cuya significancia se encuentra vinculada al valor de cambio.

Por último y no por ello menos importante, Klein desconoce realmente como se ha forjado el ideal democrático ya que no tiene una formación helénica fuerte. En efecto, cómo bien explica el profesor C. Castoriadis ${ }^{30}$, la democracia ha sido, como la geometría o mismo la filosofía un concepto nacido de Atenas. A diferencia de la mitología judeo-cristiana e incluso la reforma donde los dioses protegen a los hombres y ponen el mundo a su disposición, para los griegos el hombre era sólo parte minúscula del mundo, y entonces, no huelga decir, debía demostrar ser merecedor (conquistador) de vivir en ese mundo. Esa idea de competir constantemente para sobrevivir, lleva inevitablemente a la idea del más fuerte, expresión máxima del deporte (acción), la filosofía (pensar) y democracia (ciudad). Por lo tanto, la democracia no era un régimen de organización política sino un concepto por medio del cual cualquier ciudadano podía abolir, en asamblea, una ley si la consideraba injusta. Contextualmente, la legitimidad del rey y su senado no estaban en duda ya que la organización republicana era un concepto ajeno a la democracia. Precisamente, la democracia no denotaba masividad sino elitismo y "el gobierno de los más sabios" (aristocracia). Los griegos consideraban que aquello que se extendiera a todo el pueblo no solo podía ser perjudicial para el orden, sino que también atentaba contra la propia ciudad porque sentaba las bases para el advenimiento de una dictadura. En resumidas cuentas, es la democracia anglosajona la que considera a lo masivo como necesario. La dicotomía se da, sin dudas, en el binomio libertad versus opresión. El capital, la democracia y el mercado están inherentemente ligados. En la libertad de acción (no de pensamiento) el capital se expande ideológicamente conectando ausencias con presencias (modernidad) generando así una nueva forma de concebir el mercado y las relaciones humanas ya sea por el miedo, riesgo o indiferencia que engendra el verdadero estado de desastre ${ }^{31}$; este es el error conceptual de Klein más común en su trabajo. Por su parte, el utilitarismo, cuya tesis propugnaba una justa distribución de la felicidad para todos los ciudadanos, se encuentra acompañado al libre mercado. El concepto helénico de democracia era aristocrático ya que el mundo se concebía como un lugar peligroso, inhóspito y

\footnotetext{
${ }^{28}$ Eagleton, T. Las llusiones del Posmodernismo. Buenos Aires, Paidos, 2004.

${ }^{29}$ Op. Cit, 46

${ }^{30}$ Castoriadis, C. What shapes Greece: from Homer to Heraclitus. Seminaires 1982-1983. Human Creation II. Buenos Aires, Fondo de Cultura Economica, 2006.

${ }^{31}$ Giddens, A. Modernity and Self-Identity: Self and Society in the Late Modern Age. California, Stanford University Press, 1991. - Bauman, Z. Vida de Consumo. Buenos Aires, Fondo de Cultura Económica, 2007.
} 
ajeno a la voluntad del hombre, por lo tanto, desigual. En perspectiva, las asimetrías entre los hombres, cuya máxima expresión es la esclavitud, concentran un ideal de perfección (areté) al cual seguir en momentos de crisis. La masividad es funcional a la hegemonía, advertían los socráticos. Por tanto, extender los derechos a todos, implica un doble riesgo para la mentalidad antigua ya que ese ideal apolíneo se pierde y por lo tanto en la igualdad nace la injusticia. Existe una tendencia académica en la actualidad a denunciar sin entender, y esa tendencia es, no solo muy fuerte, sino extendida en la forma de pensamiento de los intelectuales y/o funcional a las elites que dicen denunciar. Como afirmara Zizek ${ }^{32}$, la mayoría de los académicos gozan de posiciones privilegiadas y les encanta denunciar la pobreza, no por altruismo simplemente porque de esa forma refuerzan su posición exclusiva con la certeza de tener material de denuncia ya que la pobreza es una situación históricamente estructural (imposibilidad de reclamo). Perversa en su concepción, la posición académica sobre las injusticias y los desastres no explican sus causas sino enfatizan sobre sus efectos generando mayor desinterés y confusión. En resumen, consideramos que el trabajo de Klein no solo dista de ser serio sino que además es un abordaje "pseudo-científico".

\section{Epilogo}

Hemos dado un recorrido conceptual por la manera posmoderna de comprender temor y riesgo en un mundo que apela al desastre en forma de "construcción creativa" para imponer un nuevo producto. El riesgo en tanto construcción mediática nacida del mundo especulativo y financiero se corresponde con una forma de valor. Un empresario apela al riesgo para ganar más, el valor de la plusvalía está determinado por el grado de peligrosidad en la acción. El sujeto puede ganar el doble de su patrimonio o perderlo todo sin más, iniciar una acción en este punto implica un riesgo. Luhmann no equivoca el camino cuando sugiere que todo riesgo implica una decisión previa donde el decisor tiene la posibilidad de evitar el peligro (contingencia) ${ }^{33}$; no obstante, existen circunstancias, donde incluso no tomando decisión uno debe abandonarse al concepto de "fiabilidad" de otros y en ese acto está tomando una decisión ${ }^{34}$. Por lo tanto, el riesgo y la modernidad están inextricablemente ligados hasta el punto como dice Giddens, de concebir riesgos generados por los esfuerzos para mitigar otros riesgos.

En este sentido, todo riesgo denota un peligro, exagerado o real, por medio del cual el mercado puede elaborar una respuesta y darle mayor valor a determinado bien. Las economías modernas funcionan por medio del comercio y los valores asignados para productos casi virtuales. Ese proceso de valorización excede a las mercaderías y se aplican también sobre naciones, culturas, territorios y personas.

\footnotetext{
${ }^{32}$ Zizek, S. El Títere y el Enano: en núcleo perverso del Cristianismo. Buenos Aires, Paidos, 2005

${ }^{33}$ Luhmann, N. Sociología del Riesgo. México, Universidad Iberoamericana, 2006.

${ }^{34}$ Giddens, A. Modernity and Self-Identity: Self and Society in the Late Modern Age. California, Stanford University Press, 1991
} 
Mediante un riesgo agudo, ciertos productos valen más que otros. Sin ir más lejos cuando se lee entre-líneas, la compleja relación entre los medios de comunicación y el terrorismo, dice G. Weimann ${ }^{35}$, la supuesta contradicción se resuelve o toma otro sentido. El riesgo tiene como objetivo realzar determinado valor de la sociedad, ya sea su forma de consumo o la vida misma, frente a otras formas o culturas las cuales desprecia. Los medios de comunicación por un lado inundan la pantalla y los ciber-espacios con imágenes que intentan reprimir el mensaje del terrorismo, empero ese esfuerzo no solo es en vano, sino que los mismos grupos terroristas terminan apelando a los medios para presentar sus demandas. Desde una perspectiva psicológica, el mensaje de los grupos terroristas apela a la violencia como la última de las posibilidades y a la vulnerabilidad como justificación. Incluso, algunos ciber-nautas por email tienen acceso a estos grupos e intercambian mensajes de forma totalmente libre. Los esfuerzos del estado por reprimir esta comunicación abren la posibilidad de impone una censura afectando seriamente la vida democrática, pero si se toma un rol pasivo, los riesgos de sufrir una ataque en el propio territorio son mayores.

Particularmente, vemos en este ejemplo la doble cara del riesgo. Weinmann sugiere que el periodismo y los medios forman un "teatro del terror" donde la comunicación juega un doble sentido. Sin embargo, su lectura no es correcta aun cuando si lo es su observación. Lo cierto es que, existe complicidad entre los medios y los grupos "terroristas" para acuñar y distribuir un mensaje anclado en el riesgo y el temor, pero ese discurso beneficia a ambos grupos. A occidente le permite brindar una cobertura de seguros más amplia permitiendo una ensanchamiento del capital junto a intervenciones militares e imposiciones económicas que de otra forma serían imposibles, mientras a los grupos separatistas les permite afianzar su legitimidad frente a otros actores de poder en el seno de su sociedad. Particularmente, cabe destacar, como el tabú el riesgo revitaliza cierto valor de la sociedad a pesar de generar temor. El terrorismo islamita, nos ayuda a comprender "cuan superior es el estilo de vida occidental y el respeto por la vida", respeto que los "suicidas no poseen ni por la suya propia". De esa forma, la confección de riesgos siempre remite a un discurso específico enraizados en un tiempo y territorio. Esa narrativa confiere valor a ciertas prácticas pero a la vez oculta otras.

Se nos revela en este punto de análisis una cuestión moral que hace al riesgo. Si los procesos decisorios (o cursos de acción racionales) que intentan mitigar peligros engendran ellos mismos otros riesgos, ¿qué responsabilidad se le asigna a quien sufre los riesgos y a quien los genera?. Aquellos quienes toman las decisiones en las partes especializadas de la sociedad, casi nunca enfrentan las consecuencias directas de sus decisiones sino que empujan esos efectos a quienes (alejados de la cadena decisoria) debe enfrentar el peligro. Los habitantes de Nueva Orleans seguramente poco tuvieron que ver o contribuir a la decisión de

\footnotetext{
${ }^{35}$ Weinmann, G. "The theater of Terror". Journal of Aggression, Maltreatment \& Trauma. Vol. 9 (34): 379-390, 2005
} 
las grandes cadenas de aviones de seguir utilizando combustible extraído de fósiles que empeoran al proceso de cambio climático, por medio del cual el huracán Katrina hizo su aparición. Los supervivientes y las víctimas indudablemente no estaban enfrentando riesgos sino peligros por decisiones (que éticamente) no les correspondían. Siguiendo este argumento, tanto el mercado como los medios de comunicación no visualizaron las causas de la tragedia con claridad sino que enfatizaron en los efectos ${ }^{36}$. Similar al efecto del 11/9, los medios simbólicos de la sociedad van hacia las consecuencias del evento desdibujando la responsabilidad de quienes lo provocaron. De esta manera, cada evento magníficamente decorado para asustar a la audiencia reemplaza a otro precedente. Al verse la sociedad misma incapacitada para corregir las fallas que llevaron a la tragedia, cada noticia sienta las bases para que ocurra alguna otra de iguales proporciones.

Durante el terremoto de Chile en 2011, se organizó un show mediático llamado Chile Ayuda a chile. En esta campaña solidaria, los empresarios, políticos, modelos y representantes de la cultura chilena, se congregaron para juntar fondos suficientes para iniciar la reconstrucción del país. Claro está, ninguno de los presentes adjudicó responsabilidad alguna a los constructores chilenos quienes habían vendido como "Edificios anti-sísmicos" construcciones que no lo eran ${ }^{37}$. El mercado no asume la responsabilidad por las situaciones que genera, pero no solo eso, sino encuentra en el riesgo un mecanismo capaz de darle valor a sus productos y por ende potenciar las condiciones sociales para generar cada vez más desastres. La pobreza, excusa y precondición del desastre, no es corregida ya que ella es el anverso de la riqueza y la expansión del capital.

Los desastres naturales o provocados por el hombre son fenómenos que se caracterizan por su aparición repentina. Sin embargo, la mayoría de ellos continúa afianzando las distinciones de status como así también las asimetrías de cada sociedad. B. Aguirre y E. Quarantelli, a propósito del atentado al World Trade Center en 2001, llama la atención sobre la exclusión en las listas de víctimas de inmigrantes latino-americanos. Asimismo, es común reconocer que visitantes extranjeros, y turistas por no tener una identidad acreditada al momento de la tragedia, pueden pasar sin ser identificados por un largo período. Como grupos de poder, privilegiados, los turistas en la mayoría de los casos son reclamados por sus familiares o las embajadas del país del cual son oriundos. En cambio, las minorías migrantes pasan desapercibidas ${ }^{38}$. La pobreza, es presentada por los programas de entretenimientos culturales como la responsable del desastre, ya sea por los saqueos que se suscitan u otras condiciones de vulnerabilidad.

\footnotetext{
${ }^{36}$ Augé, M. diarios de Guerra. El Mundo después del 11 de Septiembre. Barcelona, Gedisa, 2002.

${ }^{37}$ Fernádez-Montt, R. y Korstanje, M. "El discurso nacional de la Tragedia, Evaluación ex post terremoto 27 02". Revista Sincronía. Spring, 2010. Disponible en http://sincronia.cucsh.udg.mx/fernandezmonttspring2010.htm

${ }^{38}$ Aguirre, B. E y Quarantelli, E. H. "Phenomenology of Death Counts in Disasters: the invisible dead in the 9/11 WTC attack". International Journal of Mass Emergencies and Disasters. Vol. 26 (1): 19-39, 2008.
} 
Algunos especialistas como J. Nigg sostienen que la pobreza como la exclusión social repercuten en los procesos y el tiempo de recuperación luego de un efecto devastador ya que las personas no pueden acceder a las condiciones materiales que exige la reconstrucción de la ciudad. En las ocasiones en que lo hacen, son reubicados en condiciones peores a las que vivían en sitios periféricos al poder económico. El proceso de reconstrucción que deviene luego de un terremoto o desastre de otro tipo reproduce las lógicas o asimetrías materiales existentes ${ }^{39}$. Aunque en sus conclusiones, la autora reconoce que la investigación en el proceso de recuperación de una comunidad luego de un desastre se encuentra recién en una fase exploratoria y hay mucho para decir en la materia. Los procesos de recuperación, entre otras cosas, se caracterizan por una falta de línea jerárquica entre los actores y las instituciones involucradas, a veces duplicando tareas o dejando temas por cubrir ${ }^{40}$. La pobreza explica el porque de lo sucedido retornando la estabilidad a los no afectados. En principio, el mensaje de cualquier desastre es que "todos podemos ser potenciales víctimas", hecho por el cual se genera un pánico colectivo que debe ser inmediatamente regulado y contenido. Los hombres necesitan sentir que los eventos suceden por algún motivo y que no son producto del simple azar. Los medios de comunicación, en seguida, elaboran toda una serie de discursos cuyo fin es restituir las jerarquías y las asimetrías preexistentes. Se elabora el concepto de pobreza como justificativo, y contemplativo del estado de desolación, crueldad e injusticia que ha desatado la fuerza del destino. Dentro de ese contexto, los no afectados sienten el deber moral de asistir a los zonas involucradas no solo reafianzando las asimetrías materiales anteriormente mencionadas, sino subsumiéndolos en un campo de dependencia ${ }^{41}$ (Korstanje, 2010).

Los medios masivos de comunicación (preliminarmente) diseminan este tipo de estereotipos con la función de llevar calma a la población. Hasta que punto lo logran es un tema de debate que excede el objetivo central de este abordaje. Lo cierto parece ser que la dependencia simbólica y material aumenta la vulnerabilidad de los sectores excluidos. Vemos ejemplos en el terremoto de Haití en donde el paternalismo euro-americano genera los efectos contrarios que pretende paliar. A la vez que se orienta a la protección de los menores sobrevivientes por medio de la adopción genera un mercado negro de venta de bebes, a la vez que aumenta el grado de acumulación financiera de ayuda, crecen las luchas territoriales entre los sobrevivientes. La creación "de las víctimas" como potencialmente inferiores a los "no afectados" es el primer discurso político de hegemonía que deviene luego del evento traumático. Dadas las condiciones del infortunio, se atribuye a la condición del involucrado por ser de una minoría, por

\footnotetext{
${ }^{39}$ Nigg, J. "Disaster Recovery as a social process". Preliminary Paper \#219. Disaster Research Center, Universidad of Delaware, 1995.

${ }^{40}$ Nigg, J. "Policy Issues for post disaster mitigation the need for a process". Preliminary Paper \# 244. Disaster Research Center, Universidad of Delaware, 1996.

${ }^{41}$ Korstanje, M. "Caridad, Dependencia y Miedo Político: el terremoto de Haití en enero de 2010". Sincronía: revista electrónica de Estudios Culturales. Fall 2010. Disponible en www.sincronia.cucsh.udg.mx. Universidad de Guadalajara, México.
} 
ser pecador, por ser pobre etc. Damos luego de lo expuesto, por concluido el tema con la frase de M. Taussig, la cual dice mucho más que mil palabras:

El terror es lo que mantiene a estos extremos en aposición, del mismo modo que esta aposición mantiene el ritmo irregular de apatía y choque que constituye la aparente normalidad de lo anormal creada por el estado de emergencia" ${ }^{2}$.

42 Taussig, M. Un Gigante en Convulsiones: el mundo humano como sistema nervioso en emergencia permanente. Barcelona, Gedisa Editorial, 1995, p.28 